\title{
Homogenization effects on simulated pultruded glass fibre reinforced laminate under compression - from static to dynamic models
}

\author{
Nazanin Pournoori $^{1 *}$, Oscar Rodera García ${ }^{1}$, Jarno Jokinen ${ }^{1}$, Mikko Hokka ${ }^{1}$ and Mikko \\ Kanerva ${ }^{1}$ \\ ${ }^{1}$ Engineering Materials Science, Faculty of Engineering and Natural Sciences, Tampere University, \\ 33014 Tampere, Finland
}

\begin{abstract}
This study presents a numerical analysis of failure in pultruded glass fibre reinforced polymer (GFRP) with three reinforcement layers, subjected to out-of-plane compressive loadings at low and high strain rates $\left(10^{-3} \mathrm{~s}^{-1}\right.$ and $\left.10^{3} \mathrm{~s}^{-1}\right)$. The simulations targets to a computationally efficient homogenization with different element types and sizes. A single-element model was created to demonstrate the highest level of homogenization. The material properties in the homogenized model were calculated using the ESAComp (Altair) software. The 3D Hashin failure criterion was implemented as a user-defined subroutine into the finite element method using Abaqus (Simulia/Dassault Systemes) to predict the failure. The comparison between different meshes and elements shows the sufficient accuracy of the homogenized model to predict the material response at the damage onset, but the location of the crack was not accurately predicted as expected. High-rate impact simulations of the Split Hopkinson Pressure Bar tests showed that the mesh does not significantly affect the failure (strain) predicted by the homogenized model.
\end{abstract}

\section{Introduction}

Pultruded and pull-wound fibre reinforced plastics (FRP) are widely used in various highperformance structural applications owing to their low weight and high strength in the longitudinal fibre direction. However, the high fraction of longitudinal fibres and very high fibre volume fraction decrease the ultimate strength of the composite in the transverse direction. Thus, it is necessary to be able to predict the impact damage onset in the pultruded FRPs through-the-thickness direction for a wide range of strain rates.

There are several published finite element analysis (FEA) techniques to predict the failure mechanisms of composites, but the techniques for FRP materials under high rate loadings are often very complex. Also, models with high amount of details in terms of laminate structures can be overly heavy for design computations to be used efficiently in the manufacturing industry for designing large components. Therefore, it is very important to improve both the accuracy and efficiency of the FEA failure models. One of the most common techniques is

* Corresponding author: nazanin.pournoori@tuni.fi 
the homogenization of the composite lay-up in the FE models. The homogenization method has been developed for different scales from micro-scale (fibre/matrix level) [1,2] to macroscale (laminate-level) [3,4].

In this work, our focus is to study the failure prediction in GFRP laminate at the low and high strain rates $\left(10^{-3} \mathrm{~s}^{-1}\right.$ and $\left.10^{3} \mathrm{~s}^{-1}\right)$ using FEA. The target of the work is to analyse and compare the predicted damage (onset) in a highly homogenized model with different mesh densities. The analysis was performed applying the 3D Hashin failure criterion. The classical laminated plate theory (CLPT) was used to convert the elastic constants from the real lay-up to the homogenized model. The ESAComp software provides the CLPT approach for the homogenization in the laminate level, where the layers with different orientations were merged to obtain a modelled homogeneous laminate through the thickness [5].

\section{Materials and methods}

\subsection{Experimental data}

Previously presented experimental data from Pournoori et al. [6] is used as a basis for the model development and validation. In the previous work, the pultruded E-glass fibre reinforced polyester laminates were analysed under compressive loading at three different strain rates $10^{-3} \mathrm{~s}^{-1}, 1 \mathrm{~s}^{-1}$, and $10^{3} \mathrm{~s}^{-1}$. The specimens included three layers of reinforcements with a stacking sequence of $\left[0^{\circ}, 85^{\circ}, 0^{\circ}\right]$. The quasi-static tests were conducted using an Instron 8800 servo-hydraulic universal testing machine, and the high rate tests were performed by using a Split Hopkinson Pressure Bar (SHPB) device. The SHPB consists of an aluminium striker bar with a length of $300 \mathrm{~mm}$, and the incident and transmitted bars with $1800 \mathrm{~mm}$-length and $11.95 \mathrm{~mm}$-diameter.

\subsection{Finite element model}

Numerical analyses were performed using the commercial FE software Abaqus (2017). In order to study the failure of the GFRP test specimens, a homogenized model was created and subjected to compressive loading at two strain rates $\left(10^{-3} \mathrm{~s}^{-1}\right.$ and $\left.10^{3} \mathrm{~s}^{-1}\right)$ using the implicit (Abaqus/Standard) and explicit (Abaqus/Explicit) solvers. The geometry of the composite was created according to the true dimensions of the tested specimens described in ref. [6]. For the homogenized model, the material properties were calculated by the homogenization of the laminate using the ESAComp software and defined using the 'Engineering Constant' for FE models, as listed in Table 1. The Young's modulus for the low rate $\left(10^{-3} \mathrm{~s}^{-1}\right)$ simulation was 4.5 GPa based on the experiment data [6]. For the high rate $\left(10^{3} \mathrm{~s}^{-1}\right)$ simulation, the value of the stiffness was $12.35 \mathrm{GPa}$, which was calculated by a logarithmic regression of the experiments data at low and intermediate strain rates.

Table 1. Material constants of the GFRP determined for the low rate model.

\begin{tabular}{|l|c|l|c|}
\hline \multicolumn{2}{|c|}{ Engineering constants } & \multicolumn{2}{c|}{ Strength constants } \\
\hline $\mathrm{E}_{1}(\mathrm{GPa})$ & 33.06 & $\mathrm{X}_{\mathrm{t}}(\mathrm{MPa})$ & 500 \\
\hline $\mathrm{E}_{2}(\mathrm{GPa})$ & 9.03 & $\mathrm{X}_{\mathrm{C}}(\mathrm{MPa})$ & 200 \\
\hline $\mathrm{E}_{3}(\mathrm{GPa})$ & 4.50 & $\mathrm{Y}_{\mathrm{t}}(\mathrm{MPa})$ & 50 \\
\hline$v_{12}$ & 0.235 & $\mathrm{Y}_{\mathrm{C}}(\mathrm{MPa})$ & 100 \\
\hline$v_{13}$ & 0.235 & $\mathrm{Z}_{\mathrm{t}}(\mathrm{MPa})$ & 50 \\
\hline$v_{23}$ & 0.235 & $\mathrm{Z}_{\mathrm{C}}(\mathrm{MPa})$ & 100 \\
\hline $\mathrm{G}_{12}(\mathrm{GPa})$ & 3.61 & $\mathrm{~S}_{\mathrm{xy}}(\mathrm{MPa})$ & 40 \\
\hline $\mathrm{G}_{13}(\mathrm{GPa})$ & 3.61 & $\mathrm{~S}_{\mathrm{xz}}(\mathrm{MPa})$ & 26 \\
\hline
\end{tabular}




\begin{tabular}{|l|l|l|l|}
\hline $\mathrm{G}_{23}(\mathrm{GPa})$ & 3.61 & $\mathrm{~S}_{\mathrm{yz}}(\mathrm{MPa})$ & 36 \\
\hline
\end{tabular}

The test specimen model was meshed with different element types and sizes to study their effect on the failure prediction. The following mesh types and densities were used in the homogenized models: (1) the C3D8 linear element (single), (2) the C3D20 quadratic element (single), and (3) the C3D8 linear elements with a size of $0.1 \mathrm{~mm}$ (cubic) in the mesh.

\subsection{Low and high strain rate test simulation}

The low strain rate $\left(10^{-3} \mathrm{~s}^{-1}\right)$ compression test was modelled with two 3D-deformable anvils located above and below of the specimen. The anvils were meshed using the eight-node linear brick elements (C3D8) with a size of $0.2 \mathrm{~mm}$. Surface-to-surface contact was set between the specimen and the anvils. The applied boundary conditions of the model are shown in Fig. 1(a). The compression was applied using the enforced displacement equal to the experimental displacement at the failure onset point.

The SHPB test setup, including the striker, incident, and transmitted bars was simulated with their exact geometries. Three bars were meshed with the C3D8 elements with a size of $0.5 \mathrm{~mm}$ at the cross-sectional surfaces. The contacts between the interfaces of the specimen and the pressure bars were modelled using a kinematic surface-to-surface contact with the 'small sliding' interaction. The in-plane translations were restricted at the centre point of the end surfaces of the incident and transmitted bars. The impact of the striker bar to the incident bar was applied by a predefined velocity field.

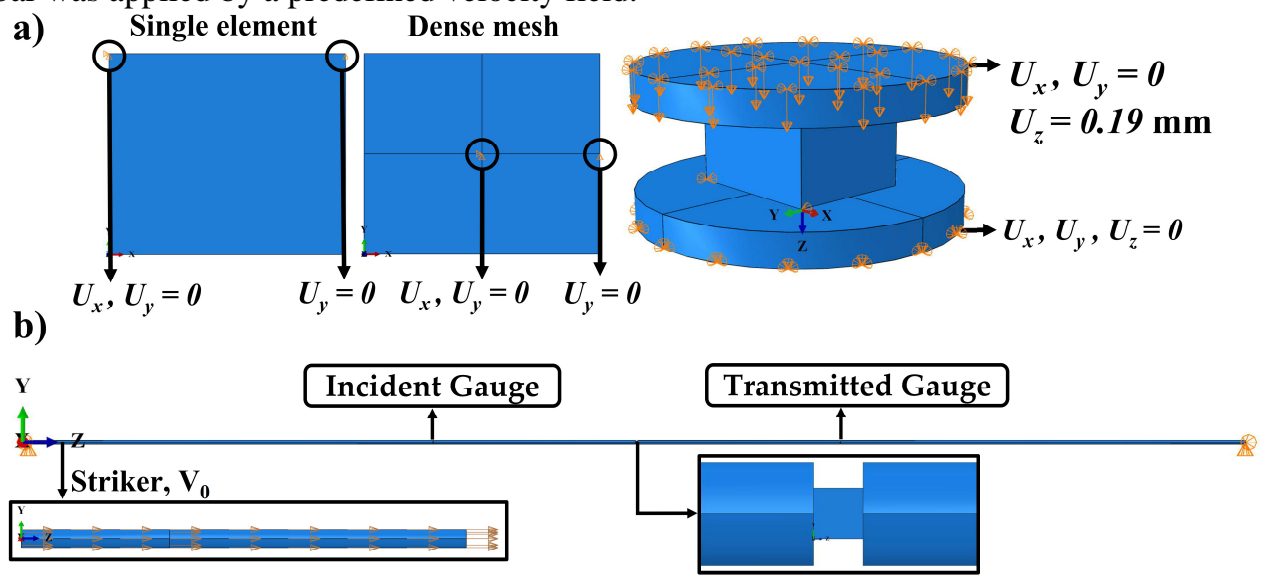

Fig. 1. The boundary conditions and loading used in the simulation of (a) the low strain rate $\left(10^{-3} \mathrm{~s}^{-1}\right)$ compression test and (b) the high strain rate $\left(10^{3} \mathrm{~s}^{-1}\right)$ SHPB compression test.

\subsection{Failure criterion}

In this study, the 3D Hashin failure criterion was used to predict the failure and governing failure modes. The criterion was implemented in the FE simulation by the user-defined Abaqus subroutines UMAT and VUMAT. The 3D Hashin criterion provokes different failure modes: (1) fibre failure (FF), tensile and compressive fibre failure, and (2) inter-fibre failure (IFF), tensile and compressive matrix failure $[7,8]$. 


\section{Results and discussion}

\subsection{Failure prediction for the low strain rate compression}

To evaluate the accuracy of the homogenized models, the results of the simulations were first analysed, and their performance was evaluated by comparing different factors at the low strain rate. Table 2 presents the displacement, strain, and force of the predicted failure onset point for the models with different mesh densities. The predicted failure of the specimen with the linear and quadratic single element models are almost the same as that obtained with the dense mesh model. However, all three models predict approximately $40 \%$ lower strain at failure than that observed in the experiment. The failure force predicted by the models with a single element is $30 \%$ lower than that observed in the experiment, while the dense mesh model predicts $36 \%$ lower force than the experimental data. It should be noted that presumably microcracking might occur in the experiment before the damage is observed visually on the surface, i.e. the real damage onset occurs at lower strain and force than the visually observed. Fig. 2(a) shows a schematic picture of the laminate, which was modelled as a single element with the highest level of homogenization. The failure predicted by the models with different mesh densities initiates due to the (compressive) matrix failure (IFF, Fig. 2(c)-(d)). The failure corresponds mainly to the out-of-plane stress component. Thus, it is not possible to determine the exact location of the failure onset in the homogenized model with the single element due to its uniform (linear) stress gradient. The model with the dense mesh predicts the failure at the free edges of the in-plane surface which are in contact with the anvils, whereas the crack onset is observed visually at the ply interfaces in the experiment, as shown in Fig. 2(b).

Table 2. FEA failure prediction by 3D Hashin criterion for the GFRP specimen at a low rate.

\begin{tabular}{|c|c|c|c|}
\hline FE homogenized model & $\delta_{I F F}(\mathrm{~mm})$ & $\varepsilon_{I F F}{ }^{*}(\mathrm{~mm} / \mathrm{mm})$ & $F_{I F F}(\mathrm{kN})$ \\
\hline Single linear element & 0.12 & 0.022 & 6.71 \\
\hline Single quadratic element & 0.12 & 0.022 & 6.71 \\
\hline Linear element, mesh 0.1 mm & 0.11 & 0.020 & 6.08 \\
\hline
\end{tabular}

*Stands for the average strain computed over a surface (nodes in the YZ plane)

a)

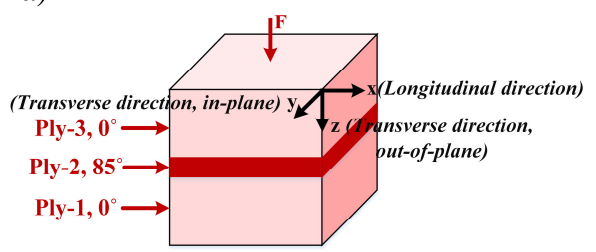

c)

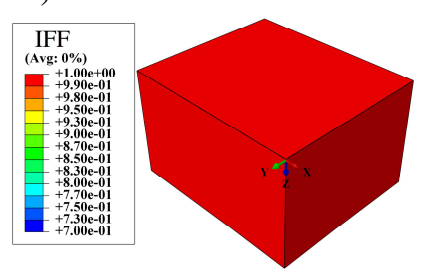

d) b)
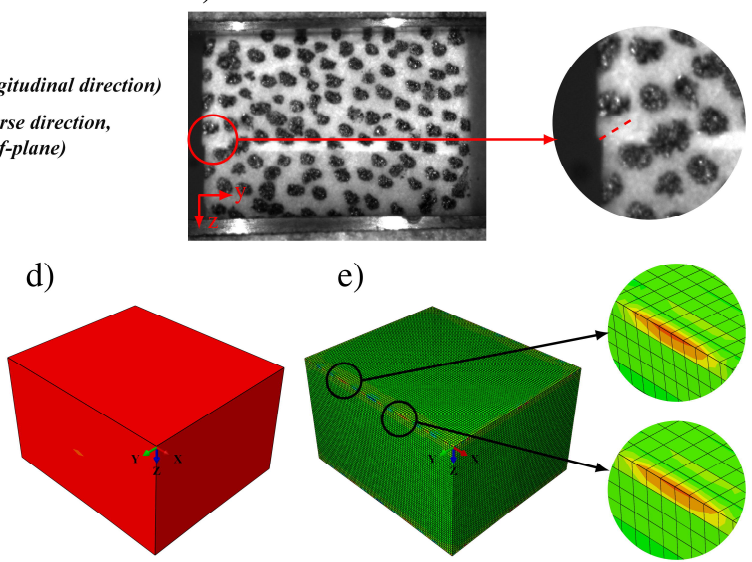

e)

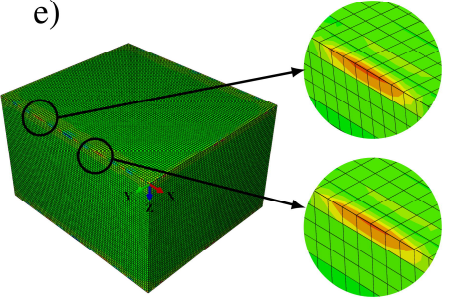

Fig. 2. (a) A schematic picture of a real specimen, (b) high speed photograph of the specimen indicating the damage onset in the experiment [6]. IFF mode at the predicted failure in the GFRP specimen at the strain rate of $10^{-3} \mathrm{~s}^{-1}$ using the homogenized model with (c) single linear element, (d) single quadratic element, and (e) linear elements in a dense mesh $(0.1 \mathrm{~mm}$, cubic). 


\subsection{Failure prediction for the high strain rate compression}

Fig. 3 shows the incident and transmitted strain pulses obtained from the SHPB experiments and the corresponding data obtained from the FEA homogenized models with different mesh densities. The simulations result fit well with the experimental data. Additionally, the two FE models predict approximately similar transmitted strains for the failure close to the end of linear response, while the experimentally observed crack onset occurs after the peak force.

The stress distribution and the failure modes obtained from the models with different meshes are shown in Figs. 4 and 5. The homogenized model with a single element predicts the linear stress gradient within the specimen, while the model with the dense mesh shows high compression on the free edges, which are in contact with the incident bar (Fig. 4(b)). The cross-section view of the model with the dense mesh (Fig. 4(c)) remarks the stresses accumulating inside the specimen that differ as much as $30 \%$ through the thickness. However, a specimen model with an exact lay-up [6] indicated a high variation of the out-ofplane stress $\left(\sigma_{33}\right)$ at the interfaces of the middle ply.

Fig. 5 shows that the IFF (matrix failure) is the dominant failure mode in the GFRP specimen at the strain rate of $10^{3} \mathrm{~s}^{-1}$. According to the out-of-plane compressive stress in the model with dense mesh, the failure occurred at the free edges, which are in contact with the incident bar (Fig. 5 (b)). It is not possible to find the exact location of crack onset in the model with a single element. Generally, it is difficult to find the exact crack onset location in high rate experiments due to the occurrence of multi crack fragments, the limited frame rate of the cameras, as well as rapid damage propagation.
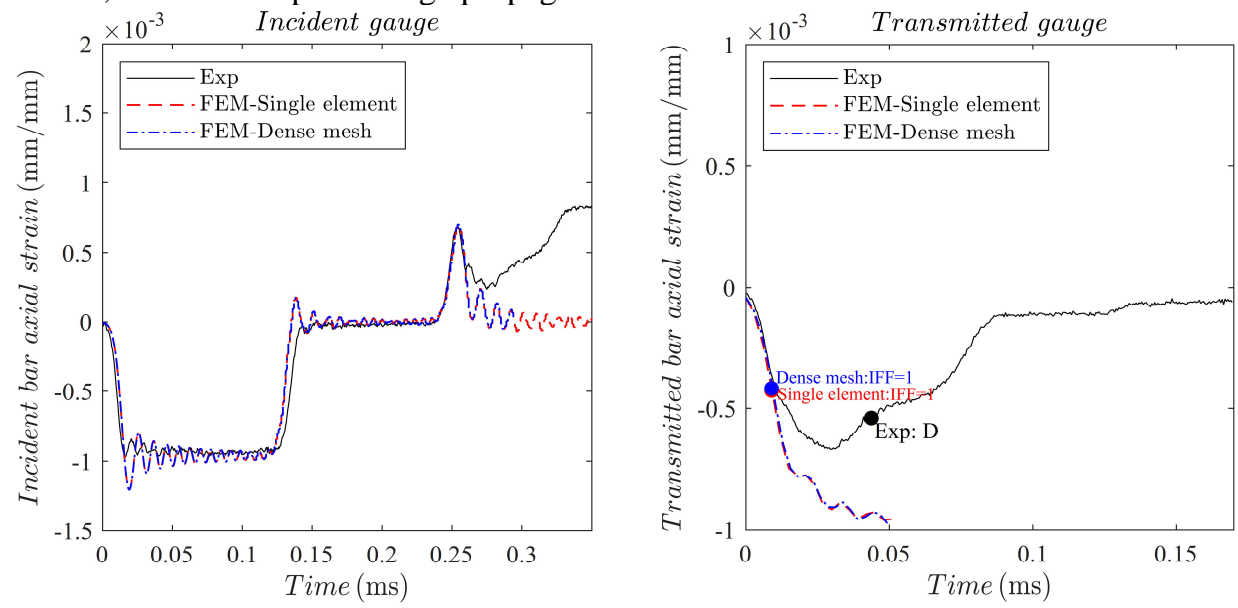

Fig. 3. Incident and transmitted strain gauge data obtained from the experiments and from the FEA homogenized models with different mesh densities.

a)

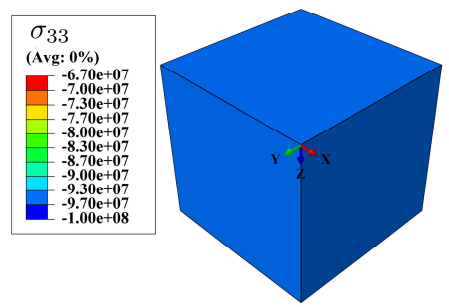

b)

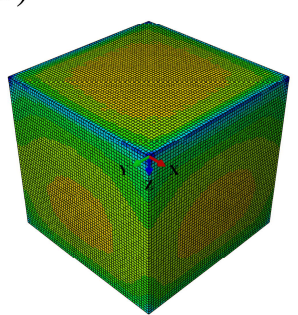

c)

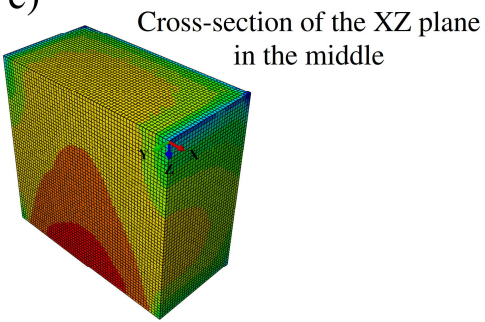

Fig. 4. Stress distributions at the predicted failure load level in the GFRP specimen at the high rate $\left(10^{3}\right.$ $\mathrm{s}^{-1}$ ) compression for the homogenized model with (a) single linear element, (b) linear elements in the dense mesh $(0.1 \mathrm{~mm}$, cubic), and (c) cross-section view of the dense mesh $(0.1 \mathrm{~mm}$, cubic) models. 
a)

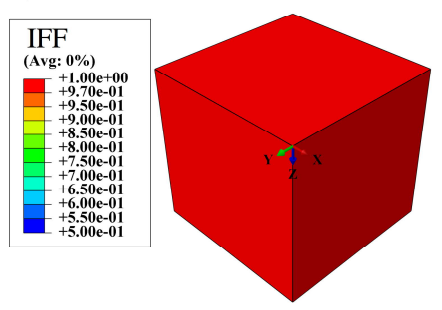

b)

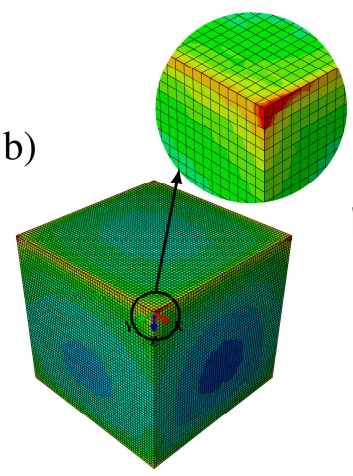

c)

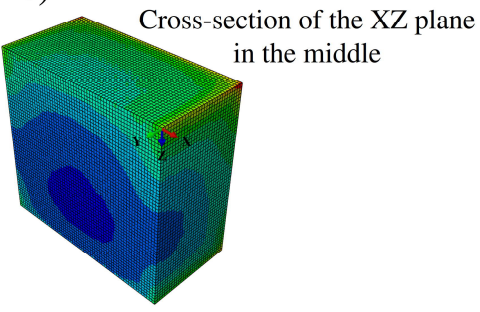

Fig. 5. IFF mode at the predicted failure in the GFRP specimen at the high rate $\left(10^{3} \mathrm{~s}^{-1}\right)$ compression for the homogenized model with (a) single linear element, (b) linear elements in the dense mesh (0.1 $\mathrm{mm}$, cubic), and (c) cross-section view of the dense mesh $(0.1 \mathrm{~mm}$, cubic) models.

\section{Conclusion}

In this work, fully homogenized composite laminate models were studied to predict the failure and experimental damage onset in a GFRP laminate subjected to out-of-plane compression at the rates of $10^{-3} \mathrm{~s}^{-1}$ and $10^{3} \mathrm{~s}^{-1}$. The performance of several models with different mesh densities was compared with the experimental data to evaluate the potential of homogenization by using the 3D Hashin failure criterion. It was shown that the homogenized models reproduced the linear-elastic mechanical response and the failure levels essentially at the same accuracy independent of the mesh density and element type. Thus, it can be said that the homogenized models are not strongly mesh-dependent in terms of the critical strain-load levels, when the effects of the (3D) element type and size are studied for compressive loading. However, there is no possibility to predict the exact location of the damage onset in the thickness direction. The experimental data in the current literature have shown that the ply interfaces under the out-of-plane loading are critical for the appearance of damage due to the high variations in the stress field inside the composite lay-up.

\section{References}

1. A.L. Kalamkarov, I.V. Andrianov, V.V. Danishevs'kyy, Appl. Mech. Rev. 62(3), 030802 (2009).

2. F. Otero, S. Oller, X. Martinez, O. Salomón, Compos. Struct. 122, 405-416 (2015).

3. P. Gaudenzi, R. Barboni, A. Mannini, Compos. Struct. 30(4), 427-440 (1995).

4. H. Ahmadi, M. Hajikazemi, W. Van Paepegem, Compos. Struct. 241, 112061 (2020).

5. M. Palanterä, J.P. Karjalainen, O. Saarela, SM98-102/344 Laminate Level Failure Criteria Based on FPF Analyses, in Proceedings Conference on Spacecraft Structures, Materials and Mechanical Testing, 4-6 November 1998, Braunschweig, Germany (ESA SP-428, February 1999).

6. N. Pournoori, G.C. Soares, O. Orell, S. Palola, M. Hokka, M. Kanerva, Int. J. Impact. Eng. 147, 103728 (2021).

7. Z. Hashin, J. Appl. Mech. 47(2), 329-334 (1980).

8. Z. Hashin, A. Rotem, J. Compos. Mater. 7(4), 448-464 (1973). 